\title{
Desde el diabólico mundo de los gentiles. Lecturas sobre un pasado muy presente en el espacio alto- andino de Potosí y Chuquisaca (Bolivia)
}

\author{
Pablo CRUZ \\ CONICET - Fundación para el Estudio del Ambiente y el Desarrollo Sostenible, San Salvador de Jujuy \\ saxrapablo@hotmail.com
}

Recibido: 26 de diciembre de 2012

Aceptado: 5 de febrero de 2013

\begin{abstract}
RESUMEN
Partiendo de las informaciones recogidas en los departamentos de Potosí y Chuquisaca en Bolivia, en este trabajo trataremos algunos aspectos relativos a la percepción de los sitios arqueológicos y al diálogo con el pasado, analizando tanto la profundidad histórica de las categorías, entidades y principios -y sus relaciones-, presentes hoy en estos espacios significantes, como su participación dentro de los intensos procesos de cambio social que tuvieron lugar durante los últimas décadas.
\end{abstract}

Palabras clave: Cultos a los muertos, ancestralidad, restos arqueológicos.

From the Diabolical World of the Gentiles: Readings on a Very Present Past in the High-Andes of Potosi and Chuquisaca (Bolivia)

\begin{abstract}
Building off data collected in the departments of Potosi and Chuquisaca in Bolivia, this paper addresses certain aspects of «chullpas» related to the perception of these archeological sites and in dialogue with the past, analyzing not only the historical profundity of the categories, entities and principles (and their relation) present today in these significant spaces, but also their participation within the intense processes of social change occurring in recent decades.
\end{abstract}

Key words: Cults to the dead, ancestry, archeological remains.

Sumario: 1. Introducción. 2. El diabólico mundo de los Chullpa. 3. Los Chullpa y el destierro de la ancestralidad. 4. Cuando los Chullpa retoman el camino de la ancestralidad. 5. A modo de conclusión. 6. Referencias bibliográficas.

\section{Introducción}

Desde el centro-sur del Perú, hasta el extremo norte de la Argentina, la voz chullpa es utilizada para designar, de manera general, tanto a los restos prehispánicos (sitios, habitaciones, tumbas), como a la antigua humanidad que habría poblado la tierra antes de la aparición del sol. En otras regiones más periféricas, como el norte de Chile y el noroeste argentino, chullpa es remplazado por los términos castellanos «gentiles»o «antiguos». Esta concepción andina del pasado cohabita hoy con otras lecturas, como la histórica/arqueológica, con las cuales entra en contradicción tanto en lo que se refiere a su periodización como a la manera de experimentar la temporalidad. En este trabajo, organizado en tres partes, exploraremos algunos aspectos del polisémico término, viendo su evolución a lo largo del tiempo. En un primer tiempo, nos adentraremos dentro del mundo de los Chullpa ${ }^{1}$ tal como es percibido en la actualidad en las áreas rurales

\footnotetext{
1 A fin de evitar confusiones en el texto, Chullpa, con mayúscula inicial, será utilizado para referirnos a la antigua humanidad pre-solar, mientras que chullpa/chullpas identificarán aquellos vestigios arqueológicos dejados por la misma.
} 
de Potosí y Chuquisaca. Seguidamente rastrearemos los orígenes del concepto y del término a la luz de las fuentes documentales coloniales analizando sus vínculos con los antiguos cultos a los antepasados. Finalmente, trataremos sobre los recientes cambios que reconducen a los antiguos Chullpa sobre el camino de la ancestralidad. Este recorrido temporal por el mundo Chullpa nos permitirá analizar tanto sus continuidades y discontinuidades, como sus relaciones con el universo de los diablos y los muertos, dentro de un marco de pensamiento andino marcado por la fluidez de sus categorías.

Los trabajos de campo que sustentan este trabajo fueron realizados de manera discontinua y, en el marco de distintos proyectos, entre los años 1995 y 2010; un período de significativos cambios sociales, políticos y económicos en toda la sociedad boliviana, los cuales tuvieron una sustancial repercusión en las comunidades campesinas. Algunos aspectos sobre los Chullpa que trataremos aquí, importantes en nuestros análisis, fueron abordados en artículos publicados pocos años atrás (Absi y Cruz 2007; Cruz 2005, 2006).

\section{El diabólico mundo de los Chullpa}

Tal como sucede en muchas regiones campesinas de los Andes, los paisajes rurales de los departamentos de Potosí y Chuquisaca en Bolivia se encuentran estructurados en torno a una multiplicidad de hitos cargados de significación, los cuales se muestran importantes en las explicaciones ontológicas del mundo. Ya sean naturales (cerros, cuevas, quebradas, manantiales, etc.) o productos de la acción humana (restos arqueológicos, calvarios, minas, cementerios, áreas pobladas, etc.), estos hitos se encuentran investidos, en mayor o menor medida, por uno de los dos principios o fuerzas animantes que rigen sobre el mundo: saqra y gloria. Vinculados estrechamente con los principios saqra, varios de estos hitos componen una de las categorías más significativas del pensamiento andino, tanto por su omnipresencia como por su polisemia: chullpa. Bajo este término se identifican hoy, tanto en aymara como en quechua, a una antigua humanidad presolar, los Chullpa, pero también a todos los vestigios materiales, o si se prefiere arqueológicos, asociados con la misma: las chullpas. Dependiendo del contexto de la formulación y, con mayor énfasis en el espacio aymara, la palabra chullpa puede expresamente designar una tumba o una momia.

El término chullpa se encuentra abundantemente en la toponimia regional señalando localidades donde generalmente yace un sitio arqueológico prehispánico; tan solo en cercanías de la ciudad de Potosí encontramos Chullpapata, Chullpahuasi, Chullpaloma, Chullpaq'hasa, etc. Asimismo, existe un ayllu llamado Chullpa integrante del gran ayllu Chayanta en Norte-Potosí, aunque desconocemos aun las razones de su nombre.

Por principio y de manera genérica, toda materialidad del pasado prehispánico es considerada como Chullpa en tanto no se encuentre asociada con los inkas, y menos aun con los españoles. Sin embargo, la definición de lo que es Chullpa y lo que no lo es, no resulta siempre evidente, pudiendo surgir incluso opiniones divergentes al interior de una misma comunidad. Tal fue el caso, por ejemplo, en Lajasmayu (Betanzos, Potosí), donde una misma tumba prehispánica fue interpretada por algunos miembros 
de la comunidad como Chullpa, mientras que para otros se trataba de un entierro de la época inka. La razón de estas diferentes interpretaciones se encontraba en la multitemporalidad del sitio -algo frecuente en los sitios arqueológicos andinos-; la tumba, una fosa simple del período formativo se encontraba localizada en el interior de una posterior ocupación inkaica.

Este caso nos muestra que los pobladores de estas regiones guardan una cierta mirada «arqueológica» sobre aquellos restos materiales que identifican como chullpa. Sin embargo, los mismos no constituyen los testimonios dejados por sus antepasados o antecesores (ñaupa), ni siquiera forman parte de la misma generación de hombres. Ellos corresponderían mas bien a otra humanidad, sustancialmente diferente y prácticamente extinta. Los Chullpa habrían vivido en un pasado remoto anterior a la salida del sol, un mundo de penumbras, donde todos sus componente, los seres, las cosas y los colores no se diferenciaban claramente (Cruz 2005, 2006; Véricourt 2000; Wachtel 1990;). Un mundo extremadamente fértil, húmedo y fluido, donde humanos, nohumanos, plantas y animales poseian la capacidad de comunicarse entre sí, los cerros se desplazaban de un lugar a otro, y se podían modelar las piedras como si fueran de arcilla. A juzgar por el tamaño de sus huesos disecados, los Chullpa son generalmente considerados como gente diminuta, aunque todos oyeron alguna vez que también existían generaciones de gigantes en su mismo mundo. Como los humanos de hoy en día, vivían en sociedad, tenían sus pueblos y en el interior de sus casas, generalmente las tumbas, atesoraban sus riquezas metálicas. A pesar de que nada estaba aun domesticado, algunas personas cuentan que ellos tenían sus chacras y sus animales; la ajara (quinua salvaje de color negro) era su principal alimento, mientras que las vizcachas, los zorros y las vicuñas eran los animales con los que mayormente se relacionaban. En algunas versiones recogidas en las zonas aymaras, los Chullpa habrían coexistido con algunas entidades no-humanas peligrosas cuando no voraces, tales que los likichiris, los hapiñuñus y los anchanchus, como también con otros animales fantásticos, cercanos a los khurus de los tejidos j'alqas (Cereceda et al. 2006 [1993]), de los cuales descenderían todos los animales que habitan hoy nuestro mundo.

En todas las versiones, la salida del sol sería el causante del ocaso de este mundo, incinerando con una luz y calor implacable la mayoría de los Chullpa. Sólo algunos pueblos que habitaban en las riberas de los lagos y zonas inundables, como los chipayas y los urus, identificados ellos mismos como los descendientes de los Chullpa, lograrían escapar de la radiación solar sumergiéndose bajo el agua, y saliendo recién por las noches. En versiones recogidas en el noroeste de la Argentina algunos antiguos habrían intentado escapar de la mortal radiación escondiéndose bajo la tierra, en sus «casitas» o en el interior de grandes vasijas cerámicas. Pero los esqueletos hallados en los entierros, las cistas (las casitas) y las urnas funerarias (las vasijas) prueban que ninguna medida fue suficiente para escapar al destino. Este cataclismo cósmico sepultaría definitivamente el mundo de los Chullpa, dando inicio a un nuevo período solar y al desarrollo de la actual generación de hombres. Y, desde entonces, los espíritus de esta primera humanidad, desprovistos ya de toda forma e identidad, encontraron refugio en el $u k h u$ pacha, el igualmente indiferenciado universo donde moran los diablos y los espíritus de los muertos. 
Sin embargo, a diferencia de los muertos recientes, los espíritus de los Chullpa rara vez salen al encuentro de aquellos seres humanos con quienes tienen, a fin de cuentas, poco que ver, salvo para velar sobre sus dominios y bienes. Tampoco participan en festividades comunales como los carnavales, no influyen en las cosechas ni en la reproducción del ganado, y rara vez son invocados durante las prácticas rituales. Sólo unas pocas personas afirmaron haber escuchado a los Chullpa, siempre por las noches, susurrando en alguna lengua incomprensible, o reparando los muros de sus antiguas viviendas.

De manera general, los campesinos de estas regiones manifiestan cautela y cierto respeto por los vestigios del mundo Chullpa que sobrevivieron al paso de los años. $\mathrm{Y}$ es que, tal como sucede en toda territorialidad, sus espíritus son celosos de sus antiguas moradas y de sus pertenencias, su presencia invisible cuida que nadie se acerque a «hurgar» en sus dominios. Por esta razón, cualquier actividad que se realice en los chullpares, sobre todo si lo que se procura es hacerse con alguno de sus «tesoros» escondidos, necesita contar con su permiso, el cual debe ser solicitado formalmente por medio del ritual. De lo contrario, uno puede agarrar el «susto»o encontrarse seriamente afectado por el influjo de su presencia. Llamada en quechua chullpasqra, el mal de Chullpa es una patología de muy amplia difusión en los Andes que se identifica en el afectado por la emergencia de granos o pequeños huesos que lastiman la piel y conducen irremediablemente a la muerte si no se recibe un tratamiento ritual adecuado. De manera semejante a otras patologías emanadas desde el inframundo, la chulpasqra no es otra cosa que una progresiva posesión, que culmina con la transformación del afectado en «Chullpa». Pero si se cumple con los gestos rituales necesarios, particularmente durante el mes de agosto, cuando la tierra se encuentra «abierta», los tesoros ocultos de los Chullpa pueden revelarse a los hombres. El emplazamiento de estos tesoros se anuncia generalmente mediante la aparición de una extraña luz, que muchos aseguran haber visto por las noches de este mes; en ocasiones se trata de una llama de fuego, en otras, un resplandor fosforecente, «como radioctividad», tal como me fue señalado en una ocasión. La esperanza de encontrar los cuantiosos botines metálicos de los Chullpa hacen cotidiana en estas regiones las prácticas del saqueo de sitios arqueológicos (huaqueo). Y de hecho, no fueron pocas las veces en que nos vimos convocados por nuestros interlocutores, en tanto que profesionales de las chullpas y siempre propietarios de potentes detectores de tesoros, para excavar en alguna ruina donde aseguraron haber observado la brillante luz.

Aparte de escucharlos o ser víctima de su influjo, en algunas ocasiones es posible ver y comunicarse con los Chullpa durante los sueños. Por ejemplo, mientras realizábamos excavaciones arqueológicas en el sitio de Jesús Valle en la periferia de Potosí, Doña Fortunata, una potente bruja potosina que por entonces frecuentábamos, «se soñó» con un indio que vestía un poncho antiguo, «de los de antes», rememoraba de manera contemplativa. Sentado sobre una roca, este Chullpa le solicitaba a la bruja que le ayudase a retornar a su hogar, en una clara alusión a los disturbios generados por las excavaciones que realizábamos. Un caso diferente se manifestó la noche previa al ascenso a la cumbre de un cerro en la zona del Salar de Uyuni donde se hallaba un santuario de altura inka. Crispín V., un indígena jalq'a originario de Irupampa (Chuquisaca), miembro del equipo, se soñó que nuestro ascenso iba acompañado 
por una banda de músicos, quienes con sus tambores, charangos y pinguyos, instrumentos propios del carnaval, tocaban alegres melodías. El sueño fue interpretado por Crispín de manera positiva: los Chullpa celebraban nuestra presencia.

Como lo señalamos anteriormente, muchos son los elementos que vinculan a los antiguos Chullpa con el universo saqra. De hecho, las características ambientales del mundo y de la época de los Chullpa, en ocasiones llamada chullpa pacha, son prácticamente idénticas a las representaciones que se tienen del inframundo: penumbras, humedad, fertilidad y una marcada indiferenciación de todos los seres que lo pueblan. La palabra saqra (saxra en aymara) designa hoy un vasto dominio, en ocasiones identificado como saqra pacha, que incluye en todos los casos al inframundo (ukhu pacha), aquellos lugares que funcionan como portales que comunican con éste (punku, qaqa, puqyu, etc.) y, de manera general, todos aquellos espacios no civilizados o desprovistos de humanidad, como los ch'in partes (lugares silenciosos), o chusaj partes (lugares vacíos). Saqra refiere igualmente a la fuerza emanada en estos espacios, la cual puede corporeizarse en algunas entidades diabólicas definidas (el Saqra, el Supay, el Diablo, etc.) o indiferenciadas (supay, saqra, diablos, almas, Chullpa, etc.). Se trata de una potente fuerza animante, salvaje y prolíficamente fértil y creativa, que envuelve en mayor o menor medida a todos los espacios y entidades del mundo. De hecho, la insaciable voracidad de la fuerza saqra sólo es controlada por la acción restrictiva y ordenadora ejercida por otra gran fuerza animante: Gloria. Ésta, por su parte, se identifica con el janaq pacha, el mundo celestial, y es encarnada por el Dios cristiano, el Sol, los astros y la mayoría de los santos benefactores.

La estrecha relación que une a los Chullpa con los dominios diabólicos de los saqra y los supay se evidencia también en el nombre que poseen ciertos sitios arqueológicos vinculados con los Chullpa: Saqraloma (loma del saqra, Yura), Supay Molino Qaqa (peña del molino del diablo, Betanzos) o Supay Cueva (cueva del diablo, Turqui), Supayñan (camino del diablo, Tinkipaya), entre muchos otros. Incluso, en algunos sitios arqueológicos de Potosí, en particular aquellos con arte rupestre, los espíritus de los antiguos Chullpa se fusionan con los diablos a modo de una amalgama. Así, los diseños rupestres de Lajasmayu son considerados como intrigantes escrituras, solo comprendidas por los ojos de los Chullpa y los supay. En estos lugares, la patología producida por el contacto con los Chullpa, el chullpasqra, se confunde igualmente con aquellas afecciones propias del universo saqra: mancharisqa (susto) y jap 'isqa (poseción, pérdida del ánimo). Por ejemplo, los pobladores de Pignasi, una comunidad localizada cerca de Betanzos (Potosí), cuentan la historia de un hombre que se vio seducido por las pinturas rupestres que llenan las paredes del abrigo rocoso llamado Bartolo cueva. De tanto frecuentar las pinturas y los demoníacos espírítus que moran en este abrigo, identificados como «bartolos» $\mathrm{y}$ «querubos», este hombre se volvió cada vez más salvaje, al punto que al cabo de un tiempo se le vio corriendo por los cerros completamente desnudo, como si fuera un animal. Es por esta razón que los pobladores de Lajasmayu evitan contemplar con demasiada frecuencia los motivos rupestres que se hallan en su comunidad. «No has de mirar, te vas a enfermar, mal has de estar y hasta loco puedes quedar», me alertaba así Don Walter durante una visita a estas pinturas rupestres realizada en 1995, antes de aclararme: «pero yo las miré hartas veces y sano estoy. Parece que es creencia no más». Otros 
ejemplos sobre la fusión entre los antiguos Chullpa y los diablos, en un repertorio que puede resultar muy extenso, fueron recogidos por Abercrombie (2005) en la región de K'ulta (Norte Potosí). Ellos cuentan que, antes la salida del sol, los Supay-Chullpa se enfrentaron a Tatala (Dios), sellando la derrota de los primeros el comienzo de la nueva era de los humanos.

Finalmente, el fuerte vínculo que une a los espíritus de los antiguos Chullpa con los diablos se pone de manifiesto en la condición subversiva, en sintonía con los principios saqra del mundo, que pueden adoptar ciertos espacios arqueológicos como los sitios con arte rupestre y las propias chullpas. Esta condición que contraría el orden social establecido, se muestra principalmente en los testimonios de sacrificios, ofrendas y mesas rituales, asociados con prácticas de brujería, magia negra y «pedidos especiales» que frecuentemente se llevan a cabo en estos espacios. Pero la intensidad de esta condición para las artes oscuras no es homogénea, varía de un sitio a otro en función de la potencia de la energía saqra emanada en los mismos. Así, la Cueva del Diablo, situada en la famosa Quebrada de San Bartolomé (Potosí), considerada en tiempos coloniales como uno de los accesos al mismo infierno (Absi y Cruz 2007), es hoy en día probablemente el principal hito de este mundo oscuro, una de las moradas del mismo Diablo. Y mientras una sólida reja metálica impide que el Demonio salga de la cueva, su interior convoca asiduamente las ch'allas y las mesas destinadas al ukhu pacha, así como todo tipo de ofrendas de brujería urbana, mensajes satánicos, y más recientemente, algunos graffitis irónicos, como aquel que dice « $i E 1$ Diablo es un cabrón!». Asimismo, sería en razón de los principios subversivos presentes en estos lugares, que los aymaras altiplánicos ocultan sus viejos fusiles, envueltos en nylon, en el interior de las tumbas arqueológicas (chullpas) presentes en sus comunidades (Cruz 2009:195).

\section{Los Chullpa y el destierro de la ancestralidad}

Si hoy en día el término chullpa se encuentra difundido sobre un amplio espacio de los Andes, es significativo que el mismo sea prácticamente inexistente en las fuentes documentales de los siglos XVI y XVII. Una de las pocas referencias tempranas conocidas aparece en el célebre diccionario aymara de Bertonio, donde la palabra chullpa es traducida como «entierro o seron donde metian sus defuntos» (Bertonio 1984 [1612]: 92). Ambos sentidos dados aquí al término chullpa se relacionan con el tratamiento que los antiguos aymaras brindaban a sus muertos. Por un lado la propia tumba o entierro, por el otro, el tejido con el cual se envolvía los cuerpos momificados. En el español de la época el serón era una espuerta o una malla de gran tamaño.

Vemos aquí ya una diferencia con algunos de los significados actuales que posee éste término, ya que chullpa no identificaba al cuerpo de los muertos, hayan estado momificados o no, ni a los restos materiales relacionados con los mismos. Según cuentan varias fuentes coloniales (p.e. Arriaga 1968 [1621]), en los Andes los restos momificados de los ancestros eran llamados por las voces de mallqui en la sierra y munao en los llanos, mientras que las tumbas eran identificadas directamente como 
«entierros» o bien bajo el polisémico vocablo nativo de «guaca/huaca» (wak'as) ${ }^{2}$. Sería recién en el siglo XVIII cuando aparecen, por ejemplo en la obra de Arzáns Orzúa y Vela (1965 [1737]), algunas menciones del término chullpa con los sentidos cercanos a los dados en la actualidad:

«Fuéronse, pues al paraje de Cantumarca, al mismo lugar donde antiguamente tenían los indios gentiles su población. Metiéronse entre las ruinas (chullpas o entierros, que había formados de tierra)» (Arzáns 1965 [1737]: 294).

Otra acepción temprana para el término chullpa, aparece en la por lo menos enigmática y controvertida obra del fraile Jesús Vizcarra (1901), quien aseguró haber reproducido los testimonios inéditos recogidos por el padre agustino Baltasar de Salas en 1628. En ella, chullpa es el nominativo dado a una antigua generación de gigantes que habría poblado la tierra en tiempos antediluvianos (Vizcarra 2010 [1901]: 142 y ss.). Más allá de la posibilidad de que el nombre chullpa haya sido un agregado tardío del imaginativo fraile Vizcarra, resulta significativo que conocidas fuentes colonia$\operatorname{les}^{3}$ se hayan referido, aunque sin hacer referencia a la palabra, a una antigua edad de gigantes anterior a la aparición de los humanos. Y esta edad de gigantes, al igual que otras edades primigenias mencionadas en las fuentes, se muestran conceptualmente muy cercanas tanto con las imágenes que los actuales campesinos poseen del mundo Chullpa, como del inframundo, espacio donde hoy residen sus espíritus. Identificadas generalmente como «tiempos antiguos», «tiempos de la primera humanidad», o bien purum pacha, esas edades se corresponderían con una época de penumbras anterior a la salida del sol, dando cuenta así de una misma matriz ontológica que se remonta a tiempos prehispánicos. Sin embargo, las versiones sobre este tiempo oscuro del mundo difieren sensiblemente entre sí, sobre todo en lo que respecta a la naturaleza de las entidades que lo poblaron. Así, mientras que en el manuscrito de Huarochirí (Taylor 2003: 27) se señala un «período antiguo» regido por los wak'as Yanañamca (Namuq negro) y Tutañamca (Namuq de la noche), para Santa Cruz Pachacuti durante la edad del purun-pacha los hapiñuñus merodeaban la tierra al acecho de víctimas humanas ${ }^{4}$. De la misma manera, Juan de Betanzos, uno de los cronistas más fiables dados los lazos familiares que mantuvo con la élite inka, se refiere a este período señalando que se trataba de antiguas «gentes» sujetas a un señor cuyos nombres cayeron en el olvido 5 .

\footnotetext{
2 Entre otros Ocaña (1969 [1605]: 65): «En esta ciudad están los mayores edificios de huacas (que son unos entierros donde los indios se enterraban), que hay en todo el Perú. Son estos sepulcros de adobes y barro; tienen unas paredes muy gruesas y debajo de tierra tantas cuevas y escondrijos y vueltas de unas partes a otras, que los laberintos de Creta quedan muy atrás con estas cosas».

3 Por solo citar algunos de ellos: Guaman Poma (1615: 925), Sarmiento de Gamboa (1943 [1572]: 36), Murúa (1961 [1613]: 70).

$4 \ll O$ porque antiguamente, en tiempo de purunpacha, dizen que los hapiñuñus andauan bissiblemente en toda esta tierra, que no abian seguridad de andar en anocheziendo, porque á los hombres y mugeres y muchachos y criaturas los llebauan arrebatandoles como tiranos infernales y enemigos capitales del género humano» (Santa Cruz Pachacuti 1879 [1613]: 235). Los hapiñuñus son unos seres monstruosos provistos de grandes senos que utilizan para matar a sus víctimas asfixiándolos.

5 «En los tiempos antiguos dicen ser la tierra e provincias de Piru oscura y que en ella no había lumbre ni día, y que había en este tiempo cierta gente en ella, la cual gente tenía cierto señor que la mandaba y a quien ella era sujeta; del nombre de esta gente y del señor que la mandaba no se acuerdan» (Betanzos 1992 [1551]: 51).
} 
Como con el ocaso del mundo de los Chullpa, la aparición del sol, acompañada en muchos casos por la acción punitiva o civilizadora de Viracocha ${ }^{6}$, marcó el final de estas edades de penumbras y el comienzo del mundo tal como lo conocemos hoy. En todas las versiones se habría tratado de un cataclismo de escala planetaria, un pachacuti en todo su sentido, que daría lugar al surgimiento y desarrollo de una nueva humanidad y una sociedad más civilizada que en los anteriores ensayos, de la cual resultarían más tarde los inkas. Sería recién a partir de esta nueva generación de hombres que se iniciarían los cultos a los ancestros y antepasados, ya sea rememorando sus existencias, o bien, celebrando sus wak'as fundacionales, sus huancas (ancestros litificados) o sus mallquis y munaos (momias). Este cambio generacional se evidencia también en el hecho de que, salvo contadas excepciones, las genealogías prehispánicas rescatadas por los cronistas españoles rara vez remontan sus orígenes antes del surgimiento de los primeros inkas.

Ahora bien, es conocido que, a la llegada de los españoles, el mundo religioso andino -y particularmente entre los inkas-, tenía uno de sus centros en los cultos a los ancestros y antepasados ${ }^{7}$. Siendo indispensable su erradicación para la conversión de las almas indígenas al cristianismo, muy tempranamente la Iglesia hizo de esta empresa una de sus principales misiones. Por un lado se instauró la práctica de enterrar los difuntos en «campo santo», en cementerios o en interior de las iglesias. Por el otro se instruyó la destrucción física de toda manifestación idolátrica, los wak'as y las momias en primer lugar. Pero ambos propósitos necesitarían mucho tiempo y esfuerzo para ser alcanzados. En efecto, varios cronistas, como Martín de Murúa, informaron cómo después de sus entierros en campo santo, los cuerpos de los difuntos indígenas eran exhumados por sus deudos y re-enterrados junto con sus antepasados en las antiguas tumbas ${ }^{8}$. Esta situación fue tan generalizada que condujo a que, bajo mandato del Virrey Francisco de Toledo, se ordenara el traslado de los poblados indígenas lejos de las sepulturas de sus antepasados?. Por su parte, Francisco de Ávila, uno de

6 Por ejemplo Betanzos cuenta que: «El cual Contiti Viracocha dicen haber salido otra vez, antes de aquelia, y que en esta primera que salió, hizo el cielo y la tierra y que todo lo dejó oscuro, y que entonces hizo aquella gente que había en el tiempo de la oscuridad ya dicha; y que esta gente le hizo cierto deservicio a este Viracocha y como della estuviese enojado, tornó esta vez postrera y salió como antes había hecho y aquella gente primera y a su señor, en castigo del enojo que la hicieron, hízole que se tornasen piedras; luego ansi como salió y en aquella misma hora, como ya hemos dicho, dicen que hizo el sol y día y luna y estrellas» (Betanzos 1992 [1551]: 52).

7 «Después de estas Huacas de piedra, la mayor veneracion, y adoracion es la de sus Malquis, que en los llanos llaman Munaos, que son los huesos, o cuerpos enteros de sus progenitores gentiles, que ellos dicen, que son hijos de las Huacas. Los quales tienen en los campos en lugares muy apartados, en los Machais, que son sus sepulturas antiguas, y algunas veces los tienen adornados con camijetas muy costosas, o de plumas de diuersos colores, o de cumbi» (Villagómez 1649: 40).

8 «Y aun en los prinsipios que se yba plantando la fé y relijión christiana entre ellos, aunque traian difuntos a enterrar en las yglesias simenterios, después de noche bolbían y los desenterraban, sin que llegase noticia a sus curas, y los llebauan a sus huacas, o a los cerros y pampas donde estauan sus antepasados y en las sepolturas antiguas, o en las casas de los difuntos, y allí los guardauan para dalles a su tiempo de comer y beuer; y entonses, haciendo juntas de sus parientes y amigos, bailaban y danzauan con gran fiesta y borrachera» (Murúa 1961 [1613]: 100).

9 «el punto en que habéis de advertir para hacer las dichas reducciones es que los dichos indios se quiten de los lugares y sitios donde tienen sus idolatrías y entierros de sus pasados por respeto de lo cual, debajo de otros colores de piedad, han engañado y engañan a los visitadores para que no les muden a adonde está»» (Anónimo 1986 [1573]: 282). 
los decanos en el combate contra la idolatría, da cuenta de la magnitud que tuvo la destrucción de los soportes materiales de los antiguos cultos indígenas:

«Yo propio, no saqué mas de treynta mil idolos por mis manos abrá treynta años, de los Pueblos del Corregimiento de Huarocheri, Yauyos, Xauxa. y Chaupihuarancas, y otros pueblos, y quemé mas de tres mil cuerpos de difuntos, que adoraban?» (Ávila 1646: 236).

De manera concomitante con la destrucción física de los wak'as y de los cuerpos momificados de los ancestros, la evangelización y, dentro de ella, la necesaria traducción a las lenguas nativas de los conceptos del cristianismo, introdujeron significativos cambios en muchas de las categorías y entidades del mundo religioso indígena. De suerte que rápidamente los cultos a los ancestros y a los antepasados, así como la veneración de sus cuerpos momificados, fueron rubricados dentro de las prácticas idolátricas y adscritos de facto a los dominios del Demonio. En efecto, tal como lo señalara Taylor (1980), el término supay (çupay, zupay, sopa, etc.), que antiguamente designaba una fuerza animante que sobrevivía a la muerte física, algo semejante a la noción occidental de alma, fue progresivamente convertido en paráfrasis de ángel bueno y malo, fantasma, enemigo del género humano, Demonio y Diablo (Estenssoro Fuchs 2003). Por su parte, el concepto del infierno subterráneo, la morada del Demonio, fue traducido al quechua como çupai huasin (casa del supay) y luego $u k h u$ pacha, el inframundo o mundo interior.

Otro ejemplo de la demonización de los cultos a los antepasados lo encontramos en las derivaciones del término saqra, el cual se convertiría con el tiempo en sinónimo de demonio y diablo, pero también como nominativo de los principios y fuerzas emanados del inframundo. En el diccionario aymara de Bertonio, sakhra es traducido simplemente como «flaco» y sakhra achachi y el apachi como «viejo o vieja que no tiene más que el pellejo», también sakhra ccharqui como «carne seca flaca» y sakhra cemito, acemita seca (pan de salvado seco). Bertonio toma como sinónimo de sakhra los términos de tucari y sakhe que traduce igualmente como flaco y desmedrado. Partiendo de estas definiciones podemos, por un lado, relacionar el término aymara $s a$ khra con los restos momificados de los ancestros y antepasados, en tanto que ellos se caracterizan precisamente por encontrarse flacos y secos como las alusiones al pan y a la carne referidas por Bertonio. Y de hecho, resulta significativo que Bertonio incluya en su diccionario la voz sakhra solo como complemento de los calificativos de flaco y seco, a manera de resaltar la condición necesaria para lograr esos estados (flaco, seco). Es relevante también que sakhra aparece para señalar la condición del «viejo o vieja que no tiene más que el pellejo» (sakhra achachi), y como complemento-superlativo en ccharqui (charque). Incluso, podemos encontrar en esta acepción de sakhra un equivalente de «momia», si tenemos en cuenta que la fórmula «carne momia» fue utilizada tanto para identificar a las momias humanas, como, de manera general, a todo cuerpo, humano o animal, resecado por el sol y el frío, o bien, a un corte de carne especial y elegida sin hueso (Dic. RAE, 1729: 186). Es interesante ver aquí otra palabra fonéticamente cercana a sakhra y que guarda igualmente tanto relación con los antiguos cultos a las momias, como con el concepto actual de saqra. Se trata de sakha, que aparece en el diccionario de Bertonio en términos como sakhahualla, «viejo, roto, gastado»; sakha, «las aberturas de la tierra, o peña de muchas concavidades»; sakha 
takha, «tierra o peña de muchas concavidades». En tanto que peña, lugar donde generalmente emanan fuerzas del inframundo -y con frecuencia espacio funerario-, sakha se relaciona a su vez con ccaca: «Fantasma que anda de noche segun dicen y toma este nombre del ruido que haze como tartamudo», ccacca hali: «Andar la fantasma» y ccaccartatha: «Estar atónito, y como fuera de sí, embelesado».

Pero la condenación de los cultos a los ancestros y a los antepasados gentiles no sólo se justificó por los fines de la evangelización y el combate de las idolatrías. Al mismo tiempo, se procuró con ello desmantelar los cimientos de las estructuras sociales indígenas, las cuales, a la llegada de los españoles, se constituían en torno a los ancestros comunes, quienes con frecuencia no eran otros que los wak'a tutelares de sus comunidades. Asimismo, desde el Inka hasta los señores locales, el hecho de que los gobernantes indígenas transmitieran de manera hereditaria el poder político, fue una razón suficiente para la veneración de sus propios antepasados. Incluso, después de la muerte de cada Inka, sus cuerpos momificados continuaban ocupando el centro de los linajes (panacas) que habían formado cuando se encontraban en vida. De la misma manera, en todos los niveles sociales, los muertos participaban activamente en la vida de cada pueblo, involucrándose con sus bultos secos en las festividades religiosas y en los rituales propiciatorios, y siendo consultados frecuentemente en las decisiones de importancia. Finalmente, en otra escala de la reflexión, pero vinculado con lo anterior, es importante tener en cuenta la intervención de los muertos y antepasados en el devenir de las sociedades andinas. Esta capacidad de los muertos, común en muchas sociedades del planeta, y que en los Andes aun reviste un importante sentido en las prácticas agrícolas, responde a una noción del tiempo en la que «lo pasado» se encuentra por delante, como el torrente de un río que viene de atrás pero va hacia adelante, según me fue contado por un campesino de Potosí. Como se muestra a continuación, esta particularidad del pensamiento andino no pasó desapercibida en las primeras traducciones de las lenguas nativas.

\begin{tabular}{|c|c|}
\hline Aymara (Bertonio 1984 [1612]) & Quechua (González de Holguín 1952 [1608]) \\
\hline Nayra: primero, o primeramente (pág. 235) & $\begin{array}{l}\text { Naupa ñapa pacha: antiguamente en tiempos } \\
\text { passados (pág. 178) }\end{array}$ \\
\hline $\begin{array}{l}\text { Nayrapacha, micca, uelhualupacha: antiguamen- } \\
\text { te (pág. 235) }\end{array}$ & $\tilde{N}$ Nupac: primero en orden (pág. 178) \\
\hline $\begin{array}{l}\text { Nayratta: la punta o principio de alguna cosa } \\
\text { aunque sea de soga y tras cosas assi (pág. } 235 \text { ) }\end{array}$ & $\begin{array}{l}\text { Naupapayamuni: ir siempre primero, o delantero } \\
\text { (pág. 178) }\end{array}$ \\
\hline Nayra: ojo, o ojo de la cara (pág. 237) & $\begin{array}{l}\text { Naupacman quepaman unanchacuni: mirar atras } \\
\text { y adelante, trocar por lo pasado lo futuro y lo } \\
\text { que puede suceder (pág. } 178 \text { ) }\end{array}$ \\
\hline Nayra: un grano de alguna semilla (pág. 237) & $\begin{array}{l}\text { Naupaqquey: mi predecessor, o el que va esta } \\
\text { delante de mi (pág. 179) }\end{array}$ \\
\hline Antepassados: nayra haque naca (pág. 54) & Antecessor: ñaupaqueycak (pág. 260) \\
\hline
\end{tabular}

La enorme gravitación social que tuvieron los cuerpos momificados entre los indígenas andinos se refleja en los arduos y prolongados esfuerzos puestos por la Iglesia en su enfrentamiento. Sin embargo, a más un siglo del desembarco de la Santa Fe, 
ellos continuarían siendo objeto de una gran devoción, tal la preocupación de Pedro de Villagómez, el VI Arzobispo de Lima:

«Y para ponderar el amor, que tienen estos á sus antepassados, y á sus memoria, se a de reparar en la significación destos nombres, conque los llaman despues de muertos, porque Munay, quiere decir el querer, la voluntad, o el amor; y Malqui es el almacigo, que se hace sembrando, para plantar lo que en el nace, y significa tambien lo que está ya nacido para el mismo efecto, que es lo que mas quiere estiman. $Y$ assi con estos nombres dan bien entender el grande amor, y veneración que tienen a sus antepassados, y con lo demas, que con sus huacas, y cuerpos muertos hacen, declaran ser afectuosos professores de sus tradiciones, superticiones, ritos, y idolatrias, y que las obseruan de muy buena gana, como imitadores, y successores suyos en ellas» (Villagómez 1649: 13).

De hecho, no sería hasta bien instaurada la Colonia, a finales del siglo XVII, cuando la Iglesia vería su labor gratificada, sobre todo gracias a los resultados obtenidos en las campañas de extirpación de idolatrías encaradas desde los comienzos de este siglo. Sería a partir del cese de los cultos indígenas a los wak'as y a los muertos, y de que la práctica del entierro de los difuntos en campo santo se convirtiría en la norma, cuando los ancestros y antepasados emprenderían el camino que los despojaría de sus nombres y de sus historias hasta convertirlos en Chullpa.

\section{Cuando los Chullpa retoman el camino de la ancestralidad}

Oriundo de Poroma (Oropeza, Chuquisaca), Fidel C. fue uno de nuestros interlocutores más cercanos en la indagación sobre la percepción del pasado prehispánico en la región de Potosí. Persona curiosa de los saberes ancestrales y comprometido con la recuperación de las antiguas «costumbres», Fidel es un activo militante del movimiento indigenista CONAMAQ (Consejo de Ayllus y Markas del Qollasuyu) ${ }^{10}$. A comienzos de 2012, Fidel fue honrado con el importante cargo de «Tata Mallku», autoridad responsable de la Comisión Gestión Territorial Indígena-Originario y Proyectos, en tanto que representante de la nación Qhara Qhara Suyu. Tanto como él, otras autoridades elegidas en el CONAMAQ son representantes de la nación qhara qhara.

Sin embargo, hasta hace pocos años no existía formalmente la nación indígena-originaria qhara qhara suyu, de la misma manera que nunca existió una nación tinkipaya, el grupo étnico con el cual Fidel se identificaba hasta entonces. Fue recién el 4 de junio de 2008, cuando los representantes de CONAMAQ de dos de los ocho ayllus que componen Tinkipaya, Pikachuri y Qaqina, reunidos en una solemne asamblea constitutiva, plantaron los jalones de la nueva nación indígena. El nombre otorgado, Qhara Qhara suyu, fue inspirado directamente por la obra de T. Platt, T. Bouysse Cassagne y O. Harris Qaraqara-Charka. Mallku, Inka y Rey en la provincia de Charcas (siglos $X V$-XVII), publicada solo dos años antes, en 2006. Basados en un fino y exhaustivo análisis de fuentes documentales coloniales, los citados autores reconstruyeron en este libro, convertido desde su aparición en una referencia para la etnohistoria andina,

10 Este movimiento, actualmente en franco enfrentamiento con el gobierno de Evo Morales, reclama el retorno a las formas ancestrales de organización política y territorial (ayllu). 
importantes aspectos del pasado prehispánico y colonial de los grupos aymaras llamados qaraqara y charka. Y a las pocas semanas de haberse puesto en circulación, el libro se encontraba ya en manos de personas comprometidas como Fidel, quienes no solo se sintieron identificados con los antiguos qaraqara, sino que encontraron en sus páginas una potente herramienta argumental, avalada por la academia, para canalizar las demandas y reivindicaciones políticas y territoriales de sus comunidades. No se trató de un caso aislado; como los tinkipayas, en los últimos años, un gran número de grupos étnicos y comunidades de los Andes bolivianos comenzaron a reformular el pasado lejano de sus territorios a partir de informaciones recuperadas en revistas de divulgación, libros académicos o directamente transmitidas por personas visitantes (promotores, investigadores, turistas, etc.), incluso por representantes del gobierno. Así, el pasado 30 de noviembre de 2012, durante la ceremonia de entrega por parte de Evo Morales de un tramo de la carretera Avaroa y Orinoca, como parte del circuito turístico del lago Poopo (Oruro), el vicepresidente Álvaro García Linera, un reconocido intelectual, ante una multitud de campesinos-indígenas-originarios de la región de Carangas, y teniendo en las manos un ejemplar del mismo libro Qaraqara-Charka, brindó un efusivo discurso sobre las antiguas glorias de la nación karanqa cuando ésta se hallaba al servicio del Inka ${ }^{11}$. El mensaje del discurso político fue evidente; se procuró resaltar el vínculo ancestral que une a los antiguos karanqa con los actuales pobladores del territorio ${ }^{12}$.

La producción de una «historia oficial» es una figura conocida y recurrente en los procesos de construcción de las identidades étnicas y nacionales. Lo que nos interesa aquí es que la reciente filiación restablecida por los qhara qhara actuales con los qaraqara históricos, como seguramente será el caso entre los actuales carangas y los antiguos karanqas, con quienes ciertamente comparten mucho más que un mismo territorio, pudo haber supuesto una contradicción y un cierto peligro con el pasado de los Chullpa, ya que los mismos se ubican en una misma temporalidad prehispánica. En efecto, aquellos mismos «chullpares» que, por ejemplo, Fidel nos llevó a recorrer en Tinquipaya, los cuales se constituyen como hitos principales en las explicaciones ontológicas sobre el mundo de los Chullpa, hoy son también los testimonios materiales de los antiguos qaraqara. $\mathrm{Y}$ es que, de la misma manera que en ciertos momentos del año (agosto) y del día (amanecer, zénit, crepúsculo) el inframundo de los muertos, los diablos y los Chullpa, se vuelve permeable con el mundo de los hombres, en ocasiones como éstas el pasado Chullpa puede acercarse con el pasado histórico sin que por lo tanto se produzca un conflicto ontológico. Esto no quiere decir que ambas versiones del pasado puedan fusionarse en una sola, ya que tal situación equivaldría a una coexistencia de los Chullpa con los antiguos seres humanos, o peor aun, ella podría implicar una filiación entre los actuales pobladores y los Chullpa, un rasgo considerado como peyorativo reservado a los urus y a los chipayas.

De la misma manera, es posible encontrar en una misma localidad más de dos versiones sobre el pasado, tal como sucede en la región de Pampa Aullagas (Oruro), declarada formalmente -y promocionada turísticamente- como «Capital Nacional de

11 La antigua nación Karanqa formaba parte, en tiempos del Inka, de una confederación que reunía otras seis naciones aymaras: Qaraqara, Charka, Quillaqa, Sura, Chicha y Chui (Platt et al. 2006: 59-69).

12 El discurso fue transmitido en todo el país por la TV oficial. 
la Atlántida». Evidentemente, en este caso esta nueva versión del pasado no provino de la academia o de los promotores estatales, sino de las investigaciones del británico Jim Allen (1998), quien sostuvo haber hallado en estos parajes del altiplano los vestigios del famoso mundo extinto. Poco importaron las voces que alertaron sobre lo descabellado de esta propuesta; el pasado atlante de Pampa Aullagas es hoy una realidad aceptada y defendida por muchos de los pobladores locales, de la misma manera que el pasado Chullpa o el pasado histórico. De hecho, para muchos las versiones atlante y Chullpa del pasado lejano guardan algunos puntos en común; aparte de las críticas académicas, ambas se refieren a antiguos mundos de abundancia destruidos por causa de cataclismos planetarios.

Así, en los últimos años varios factores contribuyeron a significativos cambios en la percepción del pasado de las poblaciones indígenas-campesinas de los Andes bolivianos. Como hemos visto, la mayor circulación de informaciones provenientes de la academia (historia, arqueología, antropología), o el surgimiento de narrativas alternativas, como la Atlántida altiplánica, son algunos de ellos. Otros factores, cuya aparición es menos reciente, se encuentran vinculados con la llamada Globalización. Trataremos sobre dos de ellos.

Desde finales de los años 1980, acompañando una serie de medidas impuestas por el Estado de corte neoliberal (cierre de minas estatales, desregulación de los mercados, etc.), cobra amplitud y se generaliza en Bolivia el concepto de «patrimonio cultural». Impulsado por el Estado y avalado por organismos internacionales como la UNESCO, se inicia desde entonces una dinámica de puesta en valor patrimonial estrechamente ligada con el desarrollo de la industria del turismo. Promoviendo a fin de cuentas la visión occidental del pasado y de la cultura, este proceso comenzó a aplicarse primero en ciudades «patrimoniales» como Potosí y Sucre, extendiéndose posteriormente, de manera progresiva, a las áreas campesinas. Fue dentro de este marco que, por ejemplo, la UNESCO declaró Patrimonio de la Humanidad al sitio arqueológico de Tiwanaku, considerado como «el centro espiritual y político de la cultura tiwanacota». Con el correr de los años, las declaratorias se multiplicarían en todo el país. Así, en 2005, la Ley No 2989 declaró patrimonio histórico y cultural de Bolivia a los chullpares y chullpas (momias) del departamento de Oruro. En muchos casos, esos pronunciamientos oficiales serían el puntapié inicial, en tanto que alternativas de desarrollo económico sustentable frente a la crisis económica, para la ejecución de proyectos de puesta en valor. Entre los proyectos de escala nacional ejecutados desde entonces, se destaca por su envergadura la restauración de 26 chullpas del río Lauca, realizada durante los años 2008 y 2009 gracias al cuantioso financiamiento de 18.000.000 de dólares aportados por la OEA (Organización de Estados Americanos). En este sentido, y desde un punto de vista económico, no solo los vestigios de los Chullpa serían considerados patrimonialmente como legados del pasado, sino que paulatinamente se convertirían también en valoradas mercancías, incorporándose de lleno dentro del mercado del turismo.

Más allá de la cuantiosa financiación destinada a los grandes hitos nacionales, esta dinámica de patrimonialización y mercantilización de la cultura se extendió por todas aquellas regiones frecuentadas por el turismo, impactando fuertemente en la vida de las poblaciones locales. Tal es el caso del salar de Uyuni, donde más de 70.000 turistas al 
año, extranjeros casi en su totalidad, lo convierten en uno de los mayores centros turísticos de Bolivia. En este enclave del altiplano sur, la propuesta turística se centra principalmente en la organización de rutas en vehículos $4 \mathrm{x} 4$, de uno a cuatro días de duración, que visitan el salar y los fabulosos paisajes circundantes de la tierra de Lípez. Unas 40 empresas operadoras de turismo gestionan los más de 400 vehículos que circulan diariamente a través del salar. Con la idea de captar algún rédito del negocio, desde hace unos diez años los pobladores campesinos de la región comenzaron a crear sus propios atractivos turísticos en torno a los vestigios prehispánicos que yacen en sus territorios, sobre todo cuevas con momias y antiguos poblados. Significativamente, respondiendo al mercado y a los lineamientos de los promotores turísticos, los campesinos del salar decidieron no valorizar turísticamente aspectos de su vida cotidiana (Cruz 2009). Así, en no muchos años, una decena de cuevas «con momias» fueron acondicionadas en distintas comunidades circundantes del salar para recibir a los turistas ávidos de exotismo $^{13}$. En su mayoría, estas cuevas exponen montajes recientes para la exhibición de momias, las cuales son exhumadas de sitios funerarios arqueológicos cercanos. Incluso, ante el deterioro del estado de conservación de las momias y su consecutiva pérdida de atractivo turístico, en algunas comunidades se efectúa un reemplazo periódico de las mismas, exhumando para ello nuevas tumbas prehispánicas. Es decir que la valorización patrimonial de estas momias depende de su participación dentro del mercado; en sus propios contextos, las momias siguen siendo chullpa.

Bien que la versión del pasado transmitida a los turistas que visitan estas cuevas es siempre la oficial, entre los pobladores locales prevalece la que se refiere a los Chullpa pre-solares. De hecho, las momias no dejan de ser llamadas en ningún momento chullpa. Esta es una de las razones por la cual cuando se refacciona una de estas cuevas, cuando se inaugura una nueva, o cuando se deposita una nueva momia, como fue el caso en la comunidad de Atulcha, se ofrece primero una ch'alla a los espíritus de los Chullpa, en las cuales aparte del alcohol y la coca, se les ofrendan «para que coman» quinua negra o ajara. Asimismo, los comuneros tratan en lo posible de evitar quedarse solos juntos a los restos momificados, dado el peligro siempre latente de verse afectados por la presencia invisible de sus espíritus. Incluso, este temor puede llegar a provocar algunos conflictos en torno a la administración de los sitios, tal como sucede en San Juan de Lípez, donde se construyó una necrópolis con varias decenas de momias expuestas, y un pequeño museo. En la necrópolis, no así en el museo, los turnos obligatorios de permanencia, destinados a la recepción de los turistas, la limpieza y el mantenimiento, son frecuentemente esquivados, aun a pesar de la sanción monetaria (multa) que ello implica, o de la suma de dinero que deben pagar a quien los remplace. Pero si las cosas se ponen demasiado «pesadas», o cuando se corre el riego de no poder controlar la energía saqra convocada por los restos momificados, de por sí ya presentes de manera natural en el interior de las cuevas, es preferible abandonar el emprendimiento, tal como sucedió con la cueva de Colchani, y perder la inversión realizada en esfuerzo y dinero. Es por ello que en la entrada de esta cueva, que en su interior expone una instalación bastante macabra de un conjunto

13 Entre otras comunidades del salar de Uyuni que exhiben momias prehispánicas se encuentran: Colchani, Coqueza, Atulcha, Aguaquiza, Chubilca, San Juan, Jirira, Tahua. 
de momias, se encuentra un cartel de madera que tiene el dibujo de un cráneo junto a la palabra aymara khakha, que como hemos visto atrás puede ser traducida como fantasma. Así y todo, estas iniciativas desarrolladas en torno a la explotación de los «recursos culturales», tal es el término utilizado por los promotores turísticos, se multiplican al ritmo creciente de la demanda.

Pero más allá de los réditos económicos obtenidos, cuyas cifras son en todos los caso inferiores a las expectativas, el impacto de la puesta en valor de cuevas con momias y sitios arqueológicos puede medirse también en la progresiva participación de los Chullpa dentro de la economías comunales, algo que no pasa desapercibido entre los pobladores locales, quienes saben muy bien que, dentro de las reglas de la reciprocidad andina, toda prestación o beneficio recibido debe ser retribuido de alguna manera. Y de la misma manera que sucede con el Demonio, el Tío de la mina, o los supay del ukhu pacha, los espíritus de los Chullpa saben bien cobrarse sus deudas.

Finalmente, otro factor se encuentra en el intenso proceso de cambio político y social que se viene desarrollando en Bolivia, cuyo principal promotor sigue siendo el presidente indígena Evo Morales Ayma. Entre otros avances sociales y políticos, este proceso condujo al establecimiento de una nueva constitución para un nuevo Estado Plurinacional que reconoce los plenos derechos territoriales, culturales, económicos y sociales de 36 naciones indígenas. El hecho de que Evo Morales, él mismo identificado como indígena aymara, haya marcado la posesión de sus dos mandatos presidenciales en consecutivas ceremonias en el sitio arqueológico de Tiwanaku y en el Palacio de Gobierno, da cuenta de la dimensión del pachacuti ideológico y social que significaron estos cambios. Más allá de sus matices new age, las dos ceremonias de toma de poder realizadas en Tiwanaku, así como las celebraciones oficiales del año nuevo aymara, o las múltiples wilanchas que inauguran los actos oficiales, deben entenderse más allá de sus retóricas políticas. Ellas oficializan en la sociedad tanto una dimensión de la religiosidad boliviana que se encontraba oculta en el campo de las creencias y costumbres campesinas, como la permeabilidad que tiene la misma para incorporar prácticas y conceptos de otras corrientes espirituales foráneas.

Brevemente nos hemos referido aquí a algunos de los factores que intervienen en el proceso actual de re-significación del pasado Chullpa. Varios otros factores en franco desarrollo que por razones de espacio no trataremos, como los programas educativos nacionales, las dinámicas migratorias, el establecimiento de iglesias evangélicas y otras corrientes religiosas, así como los medios de comunicación, hacen lo propio. Todos ellos contribuyen, de una u otra manera, a la difusión de la versión histórica del pasado, la cual reconduce a los Chullpa sobre el camino de la ancestralidad. Una marcha que parece no tener retorno y que, si bien no los conduciría hacia una nueva extinción, los aleja cada vez más del mundo de los diablos y los muertos al que ya se habían acostumbrado.

\section{A modo de conclusión}

Este trabajo no tuvo otro propósito que explorar algunos aspectos sobre el pasado Chullpa, analizando, de manera algo regresiva, su evolución en el tiempo largo. Otras 
facetas de los Chullpa quedaron madurando en el tintero y muchos otros interrogantes requieren nuevos trabajos de campo para ser desvelados. Aun así, el análisis de esta categoría del pensamiento andino permitió discernir algunos matices en las continuidades y discontinuidades de los cultos indígenas a los antepasados y en el propio concepto de ancestralidad.

Hemos visto cómo, desde la llegada de los españoles, los cultos indígenas a los muertos y a los ancestros fueron condenados a los dominios del Demonio y combatidos por tal razón. Desde entonces y de manera progresiva, el pasado anterior a los inkas sería reubicado en una edad pre-solar desprovista de la humanidad a la que pertenecemos, transformándose con el correr del tiempo toda memoria ancestral en una masa de espíritus indiferenciados. En efecto, los Chullpa comenzaron a tomar forma en la medida que se borraba una parte importante de la historia de los pueblos andinos. Sin embargo, la remembranza de un pasado de fertilidad, abundancia y, ciertamente, autonomía, quedaría latente en los espíritus de los Chullpa, resguardada en el subversivo inframundo de los diablos y de los muertos, esperando el momento apropiado para una nueva germinación. Desde entonces, en cada uno de los levantamientos indígenas que tuvieron lugar en distintas regiones de los Andes, surgirían discursos y proclamaciones sobre la necesidad de recuperar la memoria perdida de los ancestros. Estos discursos irían, con el correr de los años, perfilando un sentido histórico que aparece ya en la pluma de intelectuales indigenistas, como José María Arguedas (1911-1969, Perú) y Fausto Reinaga (1906-1994, Bolivia). Pero sería recién en las últimas décadas del siglo XX, acompañando el reconocimiento internacional de los derechos de los pueblos indígenas propulsado por organismos como la OIT y la ONU, que, en los Andes, estos recuerdos latentes comenzarían su despertar. Desde el espacio aymara llegarían los primeros vientos de cambio, en figuras de líderes indigenistas convertidos en actores principales de la política nacional, como Felipe Quispe, el «Mallku», o bien Víctor Hugo Cárdenas, quien asumiera la Vicepresidencia de Bolivia durante los años 1993-1997. La toma en posesión de la presidencia de Bolivia por Evo Morales Ayma en 2006 y su consecutiva re-elección en 2010, fue la confirmación de que, efectivamente, se estaba gestando un nuevo pachacuti en Bolivia. Es en la actual dinámica de descolonización impulsada por el Estado Plurinacional -un Vice-Ministerio de Descolonización fue creado en 2009que comenzarían a tejerse los hilos de un pasado propio, emancipador y a la altura de los cambios políticos y sociales. Sin despojarse totalmente de su carga diabólica, los indefinidos espíritus de los Chullpa retomarían entonces los senderos de la ancestralidad, recuperando en ello sus identidades colectivas y sus temporalidades humanas, entrando nuevamente en la Historia.

\section{Referencias bibliográficas}

ABercrombie, Thomas

2005 Caminos de la memoria y del poder. Etnografía e historia en una comunidad andina. La Paz: Instituto Francés de Estudios Andinos - Instituto de Estudios Bolivianos - ASDI. 
ABsi, Pascale y Pablo Cruz

2007 «La porte de la wak'a de Potosi s'est ouverte à l'enfer. La Quebrada de San Bartolomé». Journal de la Société des Américanistes 93 (2): 51-86.

AlLEN, Jim

1998 Atlantis: The Andean Solution. The Windrush Press. Gloucestershire.

Anónimo

1986 Provisión para llevar a la práctica las reducciones (disposiciones administrativas para el Virreynato). [1573]. Sevilla: Consejo Superior de Investigaciones Científicas.

Arriaga, Pablo Joseph de

1968 Extirpación de la idolatria del Piru [1621]. Biblioteca de Autores Españoles, 209. Madrid: Atlas.

Arzáns Orzúa y Vela, Bartolomé.

1965 Historia de la Villa imperial de Potosi [1737], edición de L. Hanke. Rhode Island: Brown University Press.

Ávila, Francisco de

1646 Tratado de los Evangelios que nvuestra Madre la Iglesia propone todo el año desde la Primera Dominica de Aduiento, hasta la vltima missa de difuntos, Santos de España y añadidos en el nueuo rezado... [Lima: Imprenta de Pedro de Cabrera].

BERTONIO, Ludovico

1984 Vocabulario de lengua aymara [1612]. Cochabamba: Talleres Gráficos El Buitre.

Betanzos, Juan de

1992 Suma y narración de los Yngas [1551]. Cochabamba: Editorial Fondo Rotatorio.

Cereceda, Verónica, Jhonny Dávalos y Jaime Mejía

2006 Una diferencia, un sentido. Los diseños de los textiles Tarabuco y J'alqa, $2^{\mathrm{a}}$ reimp. Sucre: Ediciones ASUR

Cruz, Pablo

2005 «El lado oscuro del mundo. Una cartografía de la percepción de los sitios arqueológicos en los Andes meridionales (Laguna Blanca, Catamarca-Argentina y Potosí Bolivia)». SIARB Boletín 19: 38-49. La Paz.

2006 «Mundos permeables y espacios peligrosos. Consideraciones acerca de Punkus y qaqas en el paisaje altoandino de Potosí, Bolivia». Boletín del Museo Chileno de Arte Precolombino 11 (2): 35-50.

2009 «Abarcas campesinas y momias for export: identidad, cultura y negocio en el salar de Uyuni». Tinkazos 12 (26): 177-197.

ESTENSSORO Fuchs, Juan Carlos

2003 Del paganismo a la santidad. La incorporación de los indios del Perú al catolicismo 1532-1750. Lima: Instituto Francés de Estudios Andinos - Instituto Riva Agüero.

GonzÁlez de Holguín, Diego de

1952 Vocabulario de la lengua general de todo el Perú llamada lengua quechua [1608]. Lima: Instituto de Historia.

MurúA, Martin de

1961 Historia general del Perú, origen y descendencia de los incas [1613]. Madrid: Joyas Bibliográficas. 
OCAÑA, Diego de

1969 Relación de un viaje por América [1605]. Madrid: Studium.

Platt, Tristan, Thérèse Bouysse-CAssagne y Olivia Harris

2006 Qaraqara-Charka. Mallku, Inca y Rey en la provincia de Charcas (siglos XVXVII): historia antropológica de una confederación aymara. La Paz: Instituto Francés de Estudios Andinos et al.

TAYLOR, Gérald

1980 «Supay». Amerindia 5: 47-63.

2003 Huarochiri: manuscrito quechua del siglo XVII. Ritos y tradiciones. Lima: Instituto Francés de Estudios Andinos - Lluvia Editores.

Sarmiento de Gamboa, Pedro

1943 Historia de los inca [1572]. Buenos Aires: Emecé Editores.

SANTACRUZ PaChacuti, Juan

1879 Relación de antigüedades deste reyno del Pirú [1613]. Madrid: Ministerio de Fomento.

VÉRICOURT, Virginie de

2000 Rituels et croyances chamaniques dans les Andes boliviennes. Les semences de la foudre. París: L'Harmattan.

Villagómez, Pedro de

1649 Carta pastoral de exortacion e instrvccion contra las idolatrias de los indios del Arçobispado de Lima. Lima: Jorge López de Herrera (Imp.).

VizCARRA FABRE, Jesús.

2010 Copacabana de los Incas [1901]. La Paz: Fundación Flavio Machicado Vizcarra Fundación Cultural Banco Central de Bolivia.

WACHTEL, Nathan

1990 Le retour des ancêtres. Les indiens uru de Bolivie, XXe-XVIe siècles. Essai d'histoire régressive. París: Gallimard. 